\title{
Task-shifting of HIV/AIDS services down the professional ladder: Current status in Ethiopia and lessons from other African countries
}

\author{
Yordanos Belayneh ${ }^{1}$, Fasil Tekola ${ }^{2}$, Marina Madeo ${ }^{3}$, Carlo Resti ${ }^{4}$
}

\begin{abstract}
This review tried to bring to light success stories and challenges of other African countries on the same topic as lesson for current endeavors in Ethiopia where the process of implementation of task shifting is in its early stage. It concluded that task shifting can help improve access, coverage and quality of HIV/AIDS related services only if other human resource, financial, health care quality issues and the need for ongoing evaluation and research are addressed. [Ethiop. J. Health Dev. 2009;23(3):234-235]
\end{abstract}

\section{Background}

Task shifting is a systematic way of shifting tasks and responsibilities from more to less specialized health workers. At present, it is being applied as a strategy for retaining skilled health workers and improving access to HIV/AIDS related services in Ethiopia and other African countries $(1,2)$.

\section{Methods}

This paper is a review of published and unpublished literature related to task shifting processes in Ethiopia and other African countries. It was conducted through desk review and online search. Focus was given to articles published during the past 5 years related to taskshifting in developing countries where existing opportunities and possible challenges were seen.

\section{Results and discussion \\ Status of the Task Shifting Process in Ethiopia \\ Ethiopia has started implementing task shifting for the rapid scale-up of HIV prevention and treatment services. The process involved shifting the tasks from physicians to health officers, from health officers to nurses and finally to community health workers $(1,2)$. \\ Task shifting in Ethiopia benefited a lot from government commitment. As a consequence, the Task-shifting Regulatory Framework, ART implementation guideline and mapping of organizations that provide HIV/AIDS services is in place. In addition, current involvement of non-governmental organizations and other non-state actors; investment in the training of different category of care providers; and clinical mentoring provide fertile ground for task shifting implementation in Ethiopia (1).}

\section{Concerns for the success of task shifting in Ethiopia}

\section{Retention measures}

In the absence of a fundamental improvement in remuneration and other measures, retention of professional or lay health workers in clinical work will be impossible. Therefore, it is critical to properly remunerate and provide adequate training, supervision and support to lay and community workers (2). For example, in Malawi it was tried to combine task shifting with human resource management and quality improvement measures that scaled-up roll-out of ART in rural and poor districts (2).

\section{Financial sustainability}

Sustainable financing is one of the major constraints because of competition from other sectors, absorptive capacity, poor governance and issues around sustainability and donor dependency. The AIDS Support Organization (TASO) program carried out in Uganda showed that field officers can effectively and efficiently perform several follow-up tasks related to ART (3). However, immense financial and human resource investments had to be made to expand the workforce (2). Moreover, once the program creates demand for ART, measures should be taken to ensure quality of the service (3).

\section{Professional competence}

In both low- and high-income countries, well-trained lay and community workers can successfully do clearly defined tasks $(2,4)$. Experiences in Zambia and Botswana illustrated that shifting the task of ART initiation to nurses has the potential to improve ART coverage $(5,6)$, and the CD4 Nurse Intervention in

\footnotetext{
${ }^{\mathrm{T}}$ Italian Cooperation Technical Assistance, P.O. Box 1349/1250, Addis Ababa, Ethiopia, Tel. +251 911 869869, Email: jordi_belayneh@yahoo.com;

${ }^{2}$ School of Public Health, Addis Ababa University, Ethiopia and Brighton and Sussex Medical School, Brighton, UK, Tel: +251911 1260 43, E-mail: fasiltekola@yahoo.com;

${ }^{3}$ Italian Development Cooperation, Embassy of Italy, P.O. Box 1105 Addis Ababa, Ethiopia, Tel. +251 11 1239601/02, E-mail: m.madeo@itacaddis.org.et;

${ }^{4}$ Italian Cooperation Technical Assistance, P.O. Box 13018 Addis Ababa, Ethiopia, Tel. +251911 414130/ +39 368

3018482, E-mail: itahsdp-hrd@ethionet.et
} 
Mozambique has resulted in a more rational use of higher-level clinical providers (7). However, there was no empirical evidence that demonstrated that the nurses could perform as safe, accountable and acceptable practitioners. Therefore, controlled trials and formative research are needed to provide empirical data on the benefits and risks of this strategy compared to traditional models (6). Task shifting might also have consequences such as imposing new responsibilities on some staff and removing tasks from others (2).

\section{Acceptability}

It is important to ensure community level acceptability of low level health workers for the success of task-shifting. An assessment of the work of lay counselors in Ghana showed that lay counselors that promote communitybased VCT for HIV had gained community approval. However, there were concerns about stigmatization of people living with HIV by the counselors and lack of confidence on confidentiality of HIV status (8).

\section{Concluding Remarks}

In conclusion, task shifting can help improve access, coverage and quality of HIV/AIDS related services in Ethiopia only if other human resource, financial, health care quality issues and the need for ongoing training, evaluation and research are addressed.

\section{Acknowledgements}

The authors acknowledge Dr Sisay Sirgu for his support in making technical documents and in giving his valuable opinion about the notion of task shifting in Ethiopia. We are also indebted to Dr Sandro Accorsi and Dr Pasquale Farese for going through the draft manuscript.

\section{References}

1. World Health Organization/UNAIDS/PEPAR. Study on Task Shifting Regulatory Framework Mapping Study in Ethiopia. Report of a WHO Expert Committee. WHO: Geneva. Technical Report Series (number- draft report), December, 2007.
2. Philips M, Zachariah R, Venis S. Task shifting for antiretroviral treatment delivery in sub-Saharan Africa: not a panacea. Lancet 2008;371:682-684.

3. Benavides B, Caffrey M. Health Workforce Innovative Approaches and Promising Practices Study. Incorporating Lay Human Resources to Increase Accessibility to Antiretroviral Therapy: a Home-Based Approach in Uganda, July 2006. Available at: http://www.capacityproject.org/images/ stories/files/promising_practices_uganda.pdf (Accessed on September 15, 2008).

4. Samb B, Cellett F, Holloway J, Damm WV, DeCock K, Dybul M. Rapid Expansion of the Health Workforce in Response to the HIV Epidemic. The New England Journal of Medicine 2007;357(24):2510-2514.

5. Stringer J, Zulu I, Levy J, Stringer E, Mwango A, Chi BH, et al. Rapid Scale-up of Antiretroviral Therapy at Primary Care Sites in Zambia. Journal of the American Medical Association 2006;296:782793

6. Miles K, Clutterbuck DJ, Seitio O, Sebego M, Riley A. Antiretroviral treatment roll-out in a resourceconstrained setting: capitalizing on nursing resources in Botswana. Bull World Health Organization 2007;85(7):555-600.

7. Gimbel-Sherr SO, Micek MA, Gimbel-Sherr KH, Koepsell T, Hughes JP, Thomas KK, et al. Using nurses to identify HAART eligible patients in the Republic of Mozambique: results of a time series analysis. Human Resource for Health 2007;5:7. doi:10.1186/1478-4491-5-7

8. Baiden F, Akanlu G, Hodgson A, Akweongo P, Debpuur C, Binka F. Using Lay Counselors to Promote Community-Based Voluntary Counseling and HIV Testing in Rural Northern Ghana: a Baseline Survey on Community Acceptance and Stigma. J Biosoc Sci. 2007;39(5):721-33. 